\title{
USO PRÉVIO DO Ro 7-1051 NA DOENÇA DE CHAGAS EXPERIMENTAL EM CAMONDONGOS*
}

\author{
Manoel Barral Neto**
}

\begin{abstract}
No presente estudo camondongos "Swiss" foram submetidos a tratamento com a droga Ro 7-1051 (N-Benzil-2-Nitro-imidazolacetamida) antes de sua inoculação com a cepa Colombiana do T. cruzi e comparados com animais inoculados com a mesma cepa e tratados em fase inicial de infecção. Com avaliação feita por parasitemia periférica, xenodiagnóstico, sub-inoculação em camondongos recém-nascidos e exame histopatológico foram obtidos me/hores resu/tados com os animais submetidos a tratamento prévio, tendo-se verificado que $55,5 \%$ dos animais permaneceram negativados durante o curso da experiência, enquanto os tratados precocemente tiveram um indice de cura de $28,5 \%$.
\end{abstract}

\section{INTRODUÇÃO}

$\mathrm{Na}$ tentativa de terapêutica específica da doença de Chagas têm-se empregado a droga Ro 7-1051 (N-Benzil-2-nitro-imidazolacetamida). Baseados nos dados fornecidos pelo Departamento de Pesquisa do Laboratório Roche ${ }^{11}$. da baixa toxicidade da droga quando comparada com a Nitrofurazona e do alto indice de atividade terapêutica em camondongos, diversos autores experimentaram clinicamente esta medicação ${ }^{7,8,10}$ com boas respost- 3 e efeitos colaterais de pequena monta, havendo contudo predominante comprometimento cutâneo e neuropático ${ }^{8}$.

Em estudo anterior Andrade e Figueira ${ }^{3}$, utilizando este agente terapêutico em camondongos infectados com a cepa Colombiana do $T$. cruzi obtiveram indice de cura de $16,7 \%$ no tratamento prolongado, concluindo pela vantagem da instituição da terapêutica especifica, principalmente na fase precoce de infecção.

Tendo em conta os melhores resultados obtidos pelo tratamento etiológico quando instituí. do em fase inicial parece interessante verificar qual o efeito obtido quando o tratamento é feito profilaticamente, isto é, antes mesmo da instalação da infecção. O presente estudo visa estabelecer o comportamento da cepa Colombiana do $T$. cruzi ao ser inoculada em camondongos que já estão em uso do Ro 7-1051, e serão avaliados .; níveis parasitêmicos, desenvolvimento de lesões tissulares e determinados os indices de cura comparativamente com os obtidos no tratamento precoce da infecção.

\section{MATERIAL E MÉTODOS}

\section{Generalidades}

Utilizaram-se camondongos "Swiss", de linhagem não determinada, com peso médio inicial de $10 \mathrm{~g}$, mantidos no Biotério da Fundação Gonçalo Muniz com dieta padrão e água "ad libitum".

A. Cepa - A cepa do T. cruzi utilizada foi a Colombiana, isolada de paciente da Colombia e estudada em camondongos $\mathrm{C} 3 \mathrm{H}$ por Federici e Cols ${ }^{6}$, e posteriormente caracterizada morfo-bio e histologicamente por Andrade e Cols ${ }^{1}$; a

* Trabalho apresentado no XIV Congresso da Sociedade Brasileira de Medicina Tropical.

* Médico-residente do Departamento de Patologia Setor de Patologia experimental da Faculdade de Medicina da UFBa. 
progressiva com piques parasitêmicos entre $\mathbf{2 5}$ e 30 dias.

B. Inóculo - Foram obtidos os inóculos de camondongos infectados pela cepa Colombiana, sacrificados após anestesia pelo éter e secção dos vasos axilares, utilizando-se a solução de citrato de sódio a 3,8\% como anti-coagulante. O cálculo do número de tripomastigotas foi feito pelo método de Pizzi e Praguer ${ }^{9}$, modificado por Brener ${ }^{4}$. Inoculou-se cada animal com $0,1 \mathrm{ml}$ de sangue citratado, contendo 356.440 tripomastigotas, por via intra-peritoneal.

C. Esquemas Terapêuticos - Todos os animais foram submetidos a esquemas terapêuticos semelhantes, empregando-se a droga em suspensão de goma arábica a $4 \%$, administrada por entubação esofágica em doses de 100 $\mathrm{mg} / \mathrm{kg} / \mathrm{dia}$, durante cinco dias por semana.

\section{Grupos Experimentais:}

Os animais foram divididos em três grupos experimentais assim distribuidos:

Grupo I (Controle) - Dez animais sacrificados aos 36 dias de infecção sem tratamento;

Grupo II - Dez animais infectados no 4 ọ dia de uso da droga e tratados até o 370 dia de infecção, quando foram sacrificados;

Grupo III - Dez animais com tratamento iniciado aos sete dias de infecção e mantidos até o 39 , sendo então sacrificados.

\section{Métodos para avaliação dos resultados}

A. Resposta parasitêmica - Foi realizada a contagem diária do número de formas tripomastigotas presentes no sangue periférico, em animais controles e tratados, obtido por secção da cauda, colocado entre lâmina e lamínula em gota padronizada, sendo feita a avaliação em 50 campos microscópicos de $400 \mathrm{X}$.

B. Testes de cura - Os animais que mostravam negativação da parasitemia no sangue periférico eram submetidos a xenodiagnóstico (com cinco ninfas de Rhodnius prolixus) e feita sub-inoculação de sangue em camondongos recém-nascidos. O Xenodiagnóstico foi avaliado com 30 e 60 dias e o resultado da sub-inoculação avaliado pelo exame direto do sangue periférico dos animais recém-nascidos inoculados.

C. Estudo Histopatológico - Todos os ani- mais foram sacrificados e os órgãos fixados em formalina à $10 \%$ e após inclusão em parafina corados pela Hematoxilina-Eosina para estudo microscópico.

\section{RESULTADOS}

\section{Niveis de parasitemia}

Observadas as parasitemias (Fig. 1) obtidas dos Grupos I (controle) e III (tratamento precoce) constata-se que é nitidamente menos intensa, e de negativação mais precoce a parasitemia no grupo dos animais tratados, enquanto que nos animais do grupo controle há uma ascenção progressiva da parasitemia atingindo níveis bastante elevados. Os animais do Grupo II (tratamento prévio) não chegaram a desenvolver parasitemia detectável no sangue periférico mantendo-se negativos neste exame durante todo o decorrer do estudo.

\section{Lesões histopatológicas}

No Grupo I (controle) observa-se uma miosite intensa (Fig. 2), com grandes ninhos de formas amastigotas, destruição de fibras musculares e infiltração peri-neural. Ao nível do miocárdio a intensidade da infiltração inflamatória varia de animal para animal, sendo de uma maneira geral intensa, havendo poucos parasitas.

No Grupo II (tratamento prévio) os achados do miocárdio se restringem a focos discretos de infiltrado inflamatório por vezes perivasculares, não sendo encontradas formas amastigotas do T. cruzi; ao nível da musculatura esquelética há apenas raros focos de infiltração de células mononucleares (Fig. 3) e raríssimos parasitas.

No Grupo III (tratamento precoce) os aspectos observados coincidem com os do Grupo II, parecendo ainda mais discretos os acúmulos de células inflamatórias.

\section{Indices de cura}

Levando-se em conta a parasitemia do sangue periférico, assim como os resultados dos xenodiagnósticos e sub-inoculação em camondongos recém-nascidos se determinou um índice de cura em torno de $55,5 \%$ no Grupo II (tratamento prévio) e de $\mathbf{2 8 , 5} \%$ no Grupo III (tratamento precoce). 
Efeito sobre a parasitemia do uso prévio do Ro 7-1051 em animais infectados pelo T. cruzi

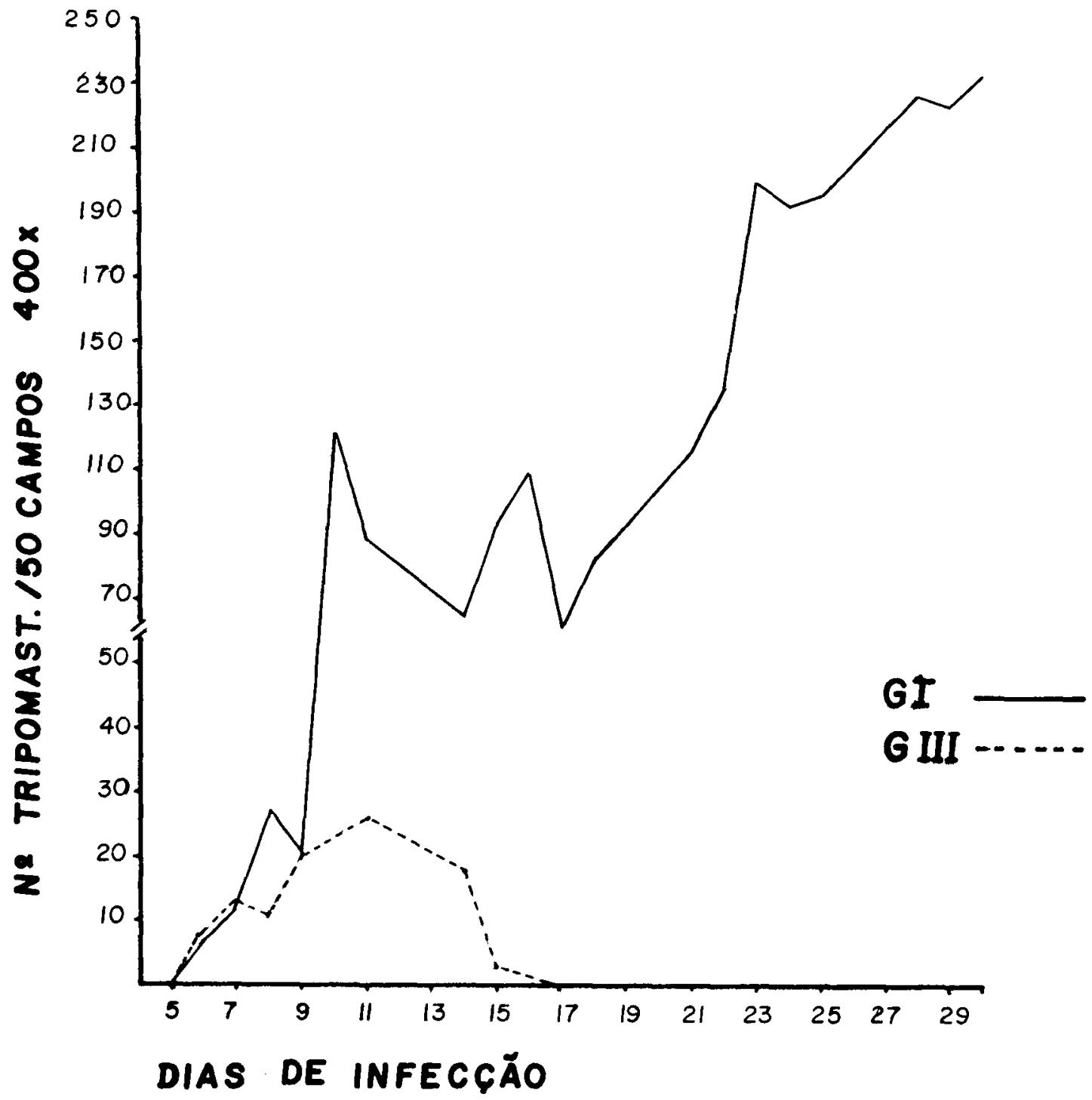

Fig. 1 - Grafico - Os niveis parasitémicos dos animais precocemente tratados (G III) foram nítidamente menos elevados e de regressão mais rápida que os dos controles não tratados (GI). Os animais prèviamente tratados não apresentaram parasitemia detectável no sangue periférico. 


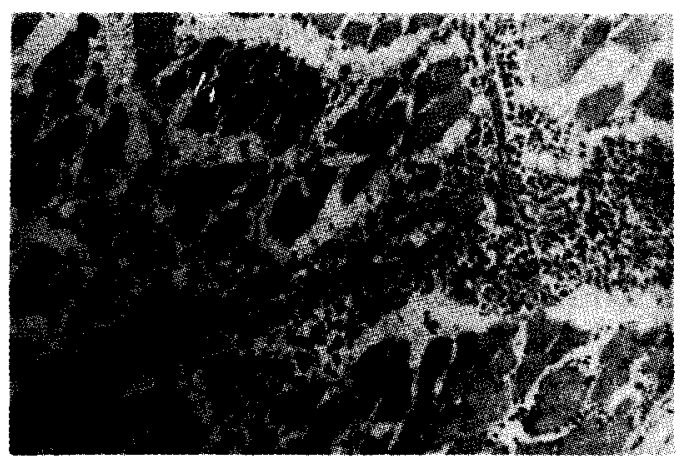

Fig. 2 - Miosite in tensa com dissociagfo e destruiç̧o de fibras musculares em animal controle sacrificado aos 36 dias de infecção sem trotemento.

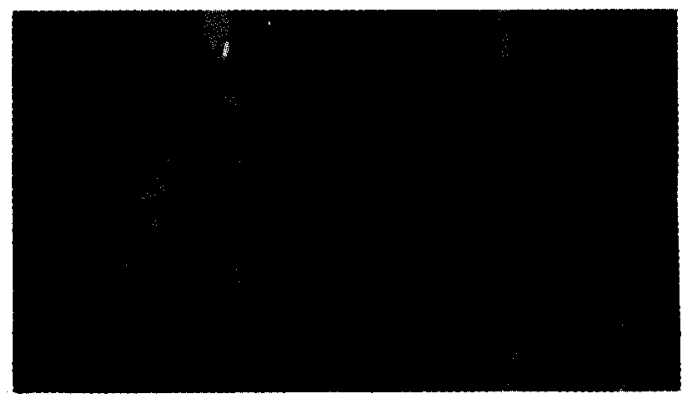

Fig 3 - Infiltracib focal de cllulas mononuchares om músculo esquelético de animal sacrificado aos 37 dias de infeção com 41 dias de tratamento.

\section{COMENTÁRIOS}

Estudo anterior de Andrade e Figueira ${ }^{3}$ de monstrou, com a mesma cepa e droga, elevação dos indices de cura para o tratamento iniciado em fase precoce de infecção quando comparado com o tratamento em fase tardia. Os resultados presentemente obtidos indicam um índice de cura parasitológica ainda maior quando o tratamento é iniciado mesmo antes da infecção do animal com o Trypanosoma cruzi. Baseados nos dados que demonstram que a ação do medicamento é ainda mais eficaz quando prévio o seu uso nos permitimos supor que a ação da droga se faz sentir também na forma sangurcola, diminuindo o número de parasitas a se estabelecer na forma amastigota. Trata-se pois de efetuar, com o tratamento prévio, uma diminuição da carga parasitária a atingir os tecidos, o que aumenta a possibilidade de cura destes animais. A ação de compostos ativos sobre formas sanguícolas havia sido estudada por Brener ${ }^{5}$ após inoculacão de tripomastigotas por via endovenosa em animais previamente tratados com diferentes compostos. No presente estudo a via intraperitoneal de inocula- ção permite ao parasita a penetração e o ciclo tissular, podendo-se observar a presença de lesões inflamatórias discretas nos animais previamente tratados, comparáveis com as observadas nos animais tratados precocemente.

Houve nítido efeito do tratamento prévio sobre a parasitemia que se tornou subpatente em todos os animais, com índice de cura de $55,5 \%$ enquanto em tratamento prolongado Andrade e Figueira ${ }^{3}$ obtiveram 16,7\% de cura parasitológica. Entretanto, pôde-se ainda verificar que $44,5 \%$ dos animais estavam parasitados mesmo quando submetidos a tratamento prévio o que comprova o alto grau de resistência ao tratamento da cepa Colombiana.

Embora o tratamento prévio à infecção seja vantajoso para o aumento dos índices de cura em camondongos, estes dados não permitem supor que este esquema terapêutico possa ser útil para tratamento em massa em zona endêmica, ou que se possa recomendar o uso profilático regular em áreas endêmicas, devido aos efeitos tóxicos descritos por Levi e $\mathrm{Cols}^{8}$ e à possibilidade de desenvolvimento de cepas altamente resistentes ao tratamento ${ }^{2}$; contudo podem se beneficiar destes dados pesquisadores e pessoas não contaminadas em passagem pouco prolongada por área endêmica, já que o uso da droga nestas condições serviria como fator de diminuição da probabilidade de infecção. O uso precoce de quimioterápico em casos de acidentes de laboratório parece também recomendável antes mesmo que se instalem sintomas gerais ou que se possa detectar parasitismo no sangue periférico.

\section{AGRADECIMENTOS}

Agradeço à Professora Sônia G. Andrade, as facilidades no laboratório e pela revisão do manuscrito.

\section{SUMMARY}

PROPHYLACTIC USE OF RO 7-1051 IN EXPERIMENTAL CHAGAS DISEASE IN MICE.

In the present study swiss mice received the drug Ro 7-1051 (N-Benzyl-2-Nitro-imidazolacetamide) before infection with the Colombian strain of T. cruzi and results were compared with infection with the same strain but with treatment on the 7 th day.

Evaluation was performed by means of 
parasitemia, xenodiagnosis, inoculation in new-born mice and histopathological finfings.

Resu/ts were better (55.5\% of negatives) in pretreated animals as compared to animals treated on the 6th day following infection (28.5\% cure rate).

\section{REFERÊNCIAS BIBLIOGRÁFICAS}

1. ANDRADE, S.G.; CARVALHO, M.L. \& FIGUEIRA, R.M. Caracterização morfobiológica e histopatológica de diferentes cepas do Trypanosoma cruzi. Gaz. Méd. Bahia, 70: 32-42, 1970.

2. ANDRADE, S.G.; ANDRADE, Z.A. \&FIGUEIRA, R.M. Estudo experimental sobre a residência de uma cepa do Trypanosoma cruzi ao Bay-2502. Rev. Inst. Med. Trop. São Paulo, 19: 124129, 1977.

3. ANDRADE, S.G. \& FIGUEIRA, R.M. Estudo experimental sobre a ação terapêutica da droga Ro 7-1051 na infecção por diferentes cepas do Trypanosoma cruzi. Rev. Inst. Med. Trop. São Paulo, 19: 335-341, 1977.

4. BRENER, Z. Contribuição ao estudo da terapêutica experimental da doença de Chagas. (tese). Belo Horizonte, 1961.

5. BRENER, Z. Study of the action of some active drugs against Trypanosoma cruzi blood forms. Rev. Inst. Med.
Trop. São Paulo, 13: 302-306, 1971.

6. FEDERICI, E.E.; ABELMAN, W.B. \& NEVA, F.A. Chronic and progressive myocarditis and myositis in $\mathrm{C} 3 \mathrm{H}$ mice infected with Trypanosoma cruzi. Amer. J. Trop. Hyg., 13: 272-280, 1964.

7. FERREIRA, N.O. Tratamento da infecção chagásica com o Ro 7-1051. X Congresso Soc. Bras. Med. Trop. (Curitiba, 1974) Sumário das Comunicações.

8. LEVI, G.C.; AMATO NETO, V. \& SANT' ANA, J.F. de A.B. Análise das manifestações colaterais devidas ao uso do medicamento Ro 7-1051, nitro-imidazólico preconizado para tentativas de tratamento específico da doença de Chagas. Rev. Inst. Med. Trop. São Paulo, 17: 49-54, 1975.

9. PIZZI, T. \& PRAGUER, R. Inmunidad a la sobre infección induzida mediante cultivos de Trypanosoma cruzi de virulencia atenuada. Bol. Inf. Parasit. Chilenas, 7: 20-21, 1952.

10. RASSI, A. Tentativas de tratamento etiológico da doença de Chagas com o composto Ro 7-1051 - resultados preliminares. $X$ Congresso Soc. Bras. Med. Trop. (Curitiba, 1974). Programa e sumário das comunicações.

11. ROCHE RESEARCH DEPARTMENT. Data sheet on Ro 7-1051, a new compund for oral treatment of Chagas disease. (Não publicado - sem data). 